\title{
Hepatobiliary Actinomycosis, a Rare Presentation of a Rare Disease!
}

\author{
Iayla Fatima $^{1}$, Frederick Pretorius ${ }^{2}$, Stefan Botes ${ }^{2}$, Rachel Swanwick ${ }^{2}$ \\ 1. General Surgery, St. Luke’s General Hospital, Kilkenny, IRL 2. Surgery, St. Luke's General Hospital, Kilkenny, IRL
}

Corresponding author: Iayla Fatima, shariffiayla@gmail.com

\begin{abstract}
Actinomycosis is a chronic granulomatous infection caused by opportunistic bacteria, Actinomyces. These bacteria lack virulence and cause disease when there is a breach in the integrity of the mucosa. Diagnosis of Actinomycosis is challenging and less than $10 \%$ of abdominopelvic cases are diagnosed preoperatively. The treatment involves prolonged course of antibiotics with or without removal of tissue. In this case report we will present a case of hepatobiliary actinomycosis which was managed by a combination of both surgical and
\end{abstract} medical treatment.

Categories: Pathology, General Surgery, Infectious Disease

Keywords: actinomycosis, actinomyces

\section{Introduction}

Actinomyces are gram positive, filamentous, anaerobic to microaerophilic bacteria endogenous to the oral cavity, gastrointestinal and genitourinary tracts [1]. Actinomycosis is a subacute to chronic infection caused by these organisms and is characterized by granulomatous inflammatory reaction with the formation of multiple abscess and sinuses [2]. The incidence of infection with Actinomyces is 1 in 300,000 and risk factors include age (20-60 years), male gender, immunosuppression and local tissue damage [3]. Actinomycosis most frequently involves the face and the neck (50\%) followed by abdomen (20\%) and thorax (15\%) [4]. Hepatobiliary actinomycosis is extremely rare and may present as biliary colic, acute or chronic cholecystitis or pancreatitis [5]. In this case report we present a case of hepatobiliary actinomycosis.

Review began $12 / 06 / 2020$ Review ended 12/26/2020 Published 12/31/2020

\section{○) Copyright 2020}

Fatima et al. This is an open access article distributed under the terms of the Creative Commons Attribution License CC-BY 4.0., which permits unrestricted use, distribution, and reproduction in any medium, provided the original author and source are credited.

\section{Case Presentation}

A 47-year-old female, presented to the emergency department with right upper quadrant pain, vomiting and fever for two days. She was previously known to have gallstones and was awaiting cholecystectomy for recurrent biliary colic. On examination, she was found to be tender in right upper quadrant with minimal rebound tenderness. Her liver function tests on admission showed total bilirubin $12.4 \mathrm{umol} / \mathrm{L}(2.0-21$ umol/L), alanine aminotransferase (ALT) 25 IU/L (5-33 IU/L), gamma-glutamyl transpeptidase (GGT) 44 IU/L (3-40 IU/L), alkaline phosphatase $78 \mathrm{IU} / \mathrm{L}$ (30-130 IU/L), WBC $7.7 \times 10^{9}\left(4-10 \times 10^{9}\right)$ and C-reactive protein (CRP) $32 \mathrm{mg} / \mathrm{L}(0-5 \mathrm{mg} / \mathrm{L})$. All other laboratory parameters were within normal limits. Clinical impression of acute cholecystitis was made and ultrasound was done.

Ultrasound revealed a thick-walled gallbladder, gallstones, dilated common bile duct (CBD) with intra and extrahepatic duct dilation; no stone was identified in the CBD (Figure 1A, 1B).

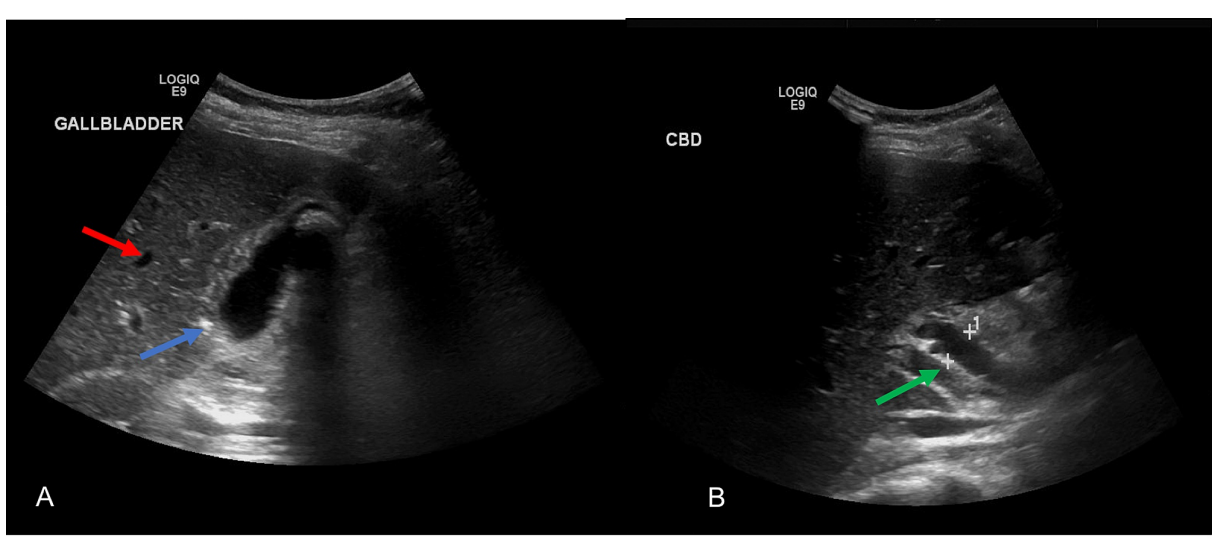

FIGURE 1: Ultrasound image of gallbladder $(\mathrm{A})$ and common bile duct 


\section{Cureus}

(B) shows intrahepatic duct dilation (red arrow), thickened gallbladder wall (blue arrow), dilated common bile duct with no filling defect (green arrow). Measurement of common bile duct is illustrated by ' + '

Following this report a magnetic resonance imaging (MRI) was performed which confirmed a dilated common bile duct but no stones were identified in the common bile duct (Figure 2). The patient underwent a cholecystectomy.

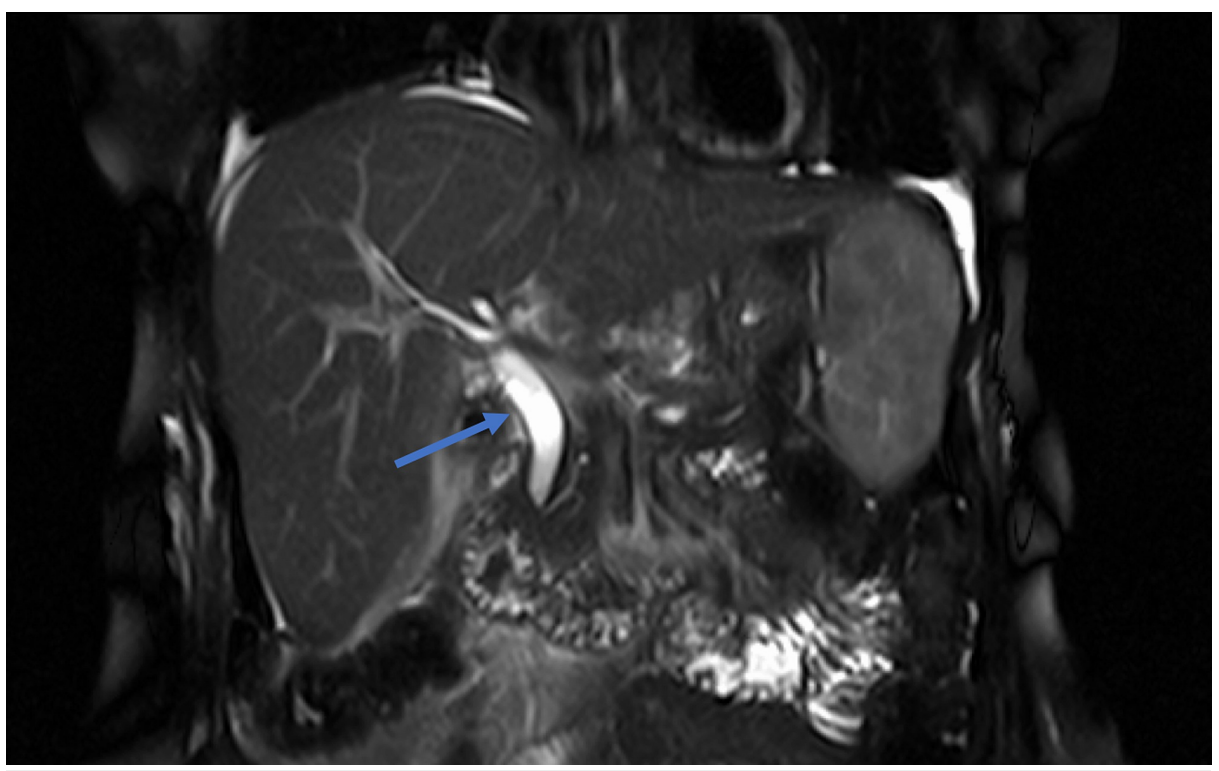

FIGURE 2: MRI showing dilated common bile duct with no filling defect (blue arrow).

Laparoscopic approach was undertaken and the omentum was found to be wrapped around the gallbladder, on mobilization of the omentum, a contained perforation of the gallbladder fundus was identified. Severe fibrosis was noted at the Hartmann's pouch making it difficult to identify the cystic duct and artery, a dilated CBD was also noted intraoperatively. Due to difficult dissection, gallbladder was opened at the level of the Hartmann's pouch, stones were removed and a subtotal cholecystectomy was done. A drain was placed in the gallbladder fossa. Apart from the histopathology of the gallbladder the peritoneal fluid (collected prior to gallbladder mobilisation) and bile aspirate were sent for gram stain and culture.

The patient had an uneventful postoperative course and the drain was removed on third postoperative day. However, the bile culture grew Actinomyces naeslundii and as per microbiologist's suggestion the patient was started on Benzylpenicillin 2.4 gm IV four times a day for two weeks followed by three months of amoxicillin. The peritoneal fluid culture and the tissue culture from the abscess cavity showed no growth and the histopathology reported active chronic cholecystitis.

\section{Discussion}

Actinomyces species encompasses more than 30 bacteria of which Actinomyces israelii is the most commonly identified in the clinical diagnosis of actinomycosis. Actinomyces are non-spore forming gram positive rods and except Actinomyces meyeri, which is short and non-branching, they all form branching filamentous rods [6]. Due to these large filaments lymphatic spread is rare [2]. The bacteria is considered opportunistic and lacks virulence causing symptoms in immunocompromised states or when there is a breach in normal defenses $[1,7,8]$.

Primary diagnosis of actinomycosis is difficult and computed tomography (CT) in abdominal actinomycosis may show thickened bowel, pelvic or peritoneal mass with extensive infiltration [9]. Bacterial culture and pathology are the mainstay in diagnosis and identification of these bacteria from a sterile site is confirmatory. Surgery is undertaken for suspected neoplasm or to drain the abscess [3].

Histopathology may reveal sulfur granules; these are basophilic masses with eosinophilc terminals on hematoxylin and eosin staining but it's present in about $75 \%$ of cases [10]. Combined antibiotic and operative treatment is curative in $90 \%$ of the cases for actinomycosis [11]. Antibiotic treatment includes IV 
Penicillin G (18-24 million units)/day for 2-6 weeks followed by amoxicillin (500-750 mg) three to four times a day for 6-12 months [12].

A similar case was reported in 2005 of a 50-year-old Sudanese male, who presented with clinical features of acute cholecystitis and was initially managed conservatively and brought back for a delayed cholecystectomy after six weeks. Although we operated on our patient on the same admission the intraoperative findings in both cases were of dense adhesions and fibrosis. Both the patients recovered well postoperatively with prolonged course of antibiotics [13].

In our case of hepatobiliary actinomycosis the proposed mechanism is the retrograde spread from duodenum into the common bile duct, liver is involved in $5 \%$ of these patients. To the best of our knowledge so far only 30 cases have been reported of gallbladder involvement and two cases of isolated CBD involvement $[4,8$, 14].

\section{Conclusions}

Our case discussed hepatobiliary actinomycosis which is extremely rare. The article highlights the difficulty in diagnosis and challenges in surgical approach. Clinicians should be aware of the intraoperative findings so that appropriate cultures are ordered and tissue is carefully examined. Currently all reported cases of gallbladder actinomycosis are diagnosed after surgical resection and the role of endoscopic retrograde cholangiopancreatography (ERCP) is not well investigated in diagnosis. Theoretically, if actinomycosis is diagnosed through culture of bile sample (obtained through ERCP), and if patient's clinical condition allows, it may be treated with prolonged course of antibiotics only.

\section{Additional Information \\ Disclosures}

Human subjects: Consent was obtained by all participants in this study. Conflicts of interest: In compliance with the ICMJE uniform disclosure form, all authors declare the following: Payment/services info: All authors have declared that no financial support was received from any organization for the submitted work. Financial relationships: All authors have declared that they have no financial relationships at present or within the previous three years with any organizations that might have an interest in the submitted work. Other relationships: All authors have declared that there are no other relationships or activities that could appear to have influenced the submitted work.

\section{References}

1. Ormsby AH, Bauer TW, Hall GS: Actinomycosis of the cholecystic duct: case report and review . Pathology. 1998, 30:65-67. 10.1080/00313029800169695

2. Hefny AF, Sebastian M, Torab FC, Joshi S, Abu-Zidan FM: Actinomycosis of the gallbladder: case report and review of the literature. Asian J Surg. 2005, 28:230-232. 10.1016/S1015-9584(09)60350-X

3. Wong VK, Turmezei T, Weston V: Actinomycosis. Bmj. 2011, 343:d6099. 10.1136/bmj.d6099

4. Filipović B, Milinić N, Nikolić G, Ranthelović T: Primary actinomycosis of the anterior abdominal wall: case report and review of the literature. J Gastroenterol Hepatol. 2005, 20:517-520. 10.1111/j.14401746.2004.03564.x

5. Thadani A, Chick J, Gollogly H, Galandauer I, Pais S: Actinomycosis of the common bile duct diagnosed by endoscopic ultrasound fine-needle aspiration. Gastroenterol Hepatol. 2010, 6:725-727.

6. Valour F, Sénéchal A, Dupieux C, et al.: Actinomycosis: etiology, clinical features, diagnosis, treatment, and management. Infect Drug Resist. 2014, 7:183-197. 10.2147/IDR.S39601

7. Cintron JR, Del Pino A, Duarte B, Wood D: Abdominal actinomycosis. Diseases Colon Rectum. 1996, 39:105108. 10.1007/BF02048278

8. Wagenlehner F, Mohren B, Naber K, Männl H: Abdominal actinomycosis. Clin Microbiol Infect. 2003, 9:881885. 10.1046/j.1469-0691.2003.00653.x

9. Lee I-J, Ha HK, Park CM, et al.: Abdominopelvic actinomycosis involving the gastrointestinal tract: CT features. Radiology. 2001, 220:76-80. 10.1148/radiology.220.1.r01j11376

10. Bennhoff DF: Actinomycosis: diagnostic and therapeutic considerations and a review of 32 cases . Laryngoscope. 1984, 94:1198-1217. 10.1288/00005537-198409000-00013

11. Ferrari T, Couto C, Murta-Oliveira C, Conceicao S, Silva R: Actinomycosis of the colon: a rare form of presentation. Scand J Gastroenterol. 2000, 35:108-109. 10.1080/003655200750024623

12. Fabre V, Bartlett JG: Actinomyces. John Hopkins Medicine, 2001.

13. World Health Organization: The Social Context of Schistosomiasis and Its Control: An Introduction and Annotated Bibliography. World Health Organization, 2008.

14. Godbole CB, Mangukiya DO, Kakkar-Kashikar R, Doctor NH: Hepatobiliary actinomycosis masquerading as malignancy. Tropical Gastroenterol. 2015, 35:253-256. 10.7869/tg.226 